\section{PA-151 FROM LABORATORY RESEARCH TO THE PUBLIC: SCIENCE COMMUNICATION FOR POLICY, RESEARCH COMMUNITY AND PUBLIC}

Emily Kabuye, Tom Lutalo, Pontiano Kaleebu, Edward Mbidde. UVRI, Uganda

10.1136/bmjgh-2016-000260.177

Background The Government of Uganda uses empirical evidence for policy formulation. The Uganda Virus Research Institute (UVRI) and the International Association of National Public Health Institutions (IANPHI) trained journalists and scientists to communicate research processes and findings to the public. This improved the capacity to communicate important information during outbreaks and to disseminate research findings as part of policy formulation.

Methods Through training workshops, 30 research scientists including study coordinators, research officers and principal investigators interacted with 12 health reporters from various media houses. Training covered writing policy briefs and press releases. Attendees were taken through the 'dos and don'ts' when being interviewed by television/radio journalist while journalists were trained in basic epidemiology terms and research processes. They analysed research papers to find different story angles. They conducted mock media talk shows for television and radio and these sessions were reviewed by all those in attendance, identifying areas for improvement.

Results Key findings revealed that journalists do not ably write about research findings because they do not understand the scientific research procedure. Training journalists on health research communication, ethical issues and research procedure enabled them to appreciate the scientific research process. Continued interaction was found to be of help to articulate research findings for health journalist before they are presented in print and audio media for the wider audience/public. This method built capacity of participating scientists to communicate to the lay audiences. It also helped the scientists plan for the media and policy makers during future dissemination of their research findings.

Conclusions Meaningful engagement of journalists and the public by scientists results in proper understanding of the ethical and scientific research procedure. This calls for systematic investment by research organisations and, during proposal development, budgeting for communication and knowledge translation of research findings to benefit policy makers and the wider research community. 